\title{
En torno a un patio La configuración espacial productiva de las fábricas de tabacos en España y aproximaciones a su influencia en el continente americano
}

\author{
Carolina Castañeda López \\ Universidad Politécnica de Madrid, España
}

Recibido: 29 de noviembre de 2015 / Aprobado: 2 de febrero de 2016

La importación del modelo de manufactura francesa colbertiana en España promovió el establecimiento de las reales fábricas en la geografia peninsular a partir del siglo XVII. Los primeros planteamientos proyectuales que abordaban este nuevo tema espacial se vieron influenciados por referentes provenientes de otros tipos arquitectónicos y por la condición manufacturera de las primeras industrias. Las fábricas de tabacos en España se materializaron a través de invariantes que trascendieron a lo largo del tiempo como recursos proyectuales propios de la producción edilicia del monopolio tabacalero. El patio como organizador del espacio se emplearía también en las primeras fundaciones de reales fábricas de tabacos americanas del siglo XVIII.

patrimonio industrial arquitectónico, fábricas de tabacos, espacio productivo, referentes tipológicos, configuración claustral

\section{Around a Courtyard. Productive Spatial Arrangement of Tobacco Factories in Spain and Approaches to their Influence in the American Continent}

The import of the French Colbertian manufacturing model in Spain promoted the establishment of Royal Factories in the peninsular geography from the XVIIth century. The first project plans addressing this new spatial issue were influenced by the use of models coming from other architectural types and by the manufacturing condition of the first industries. Tobacco Factories in Spain were architecturally materialized through a series of invariants transcending time as project resources related to the particular building production of the tobacco monopoly. Among them, the courtyard was used as an organizing principle of space, not only for the Spanish case, but also for the first establishments of the Royal Tobacco Factories in America in the XVIII ${ }^{\text {th }}$ century.

architectural industrial heritage, tobacco factories, productive space, typological references, courtyard configuration 


\section{La CASUISTICA DE LAS FÁbRICAS DE TABACOS EN ESPAÑA Y SUS DIMENSIONES DE INTERPRETACIÓN PATRIMONIAL}

La importación del tabaco desde el continente americano y el inicio de su consumo en España constituyeron el origen de la creación de factorías de producción tabacalera controladas por la Corona, que instauró un régimen hacendístico especial con el establecimiento del estanco del tabaco en el siglo XVII. Con la expansión del consumo de los productos tabacaleros y el pernicioso contrabando que se instalaba en los puertos peninsulares a los que llegaba la materia prima, la renta de tabacos tomaría conciencia desde el siglo XVIII de la importancia de extender una red productiva que afianzase su posición a escala territorial y que apoyase el estanco sobre la fabricación del tabaco ${ }^{1}$. Finalmente, la privatización del sector a finales del siglo XX supuso el cierre de la mayor parte de las tabacaleras centenarias remanentes, que constituían una rémora para la producción, dejando en el paisaje urbano espacios abandonados que pasarían a valorarse, por sus cualidades históricoculturales, como bienes patrimoniales industriales.

A pesar de su variada casuística, la lectura proyectual de las fábricas de tabacos españolas indica la presencia de invariantes arquitectónicos comunes pertenecientes a las diversas dimensiones -territorial, urbana, arquitectónica, productiva-espacial y humana- que conforman esta herencia industrial construida. Centrando la cuestión en la concepción de la organización del espacio interior, el patio surge como elemento recurrente en sus diversas variantes, tomado como referente proveniente de otros tipos arquitectónicos de muy diverso carácter y que trascendió como recurso proyectual a lo largo de la historia del monopolio hacendístico tabacalero en España.

1 La investigación de la que forma parte el presente artículo centra las hipótesis sobre un marco temporal acotado - desde mediados del siglo XVIII al primer tercio del siglo XX-, al que pertenecen las fundaciones de las fábricas de tabacos de Sevilla, Cádiz, Alicante, A Coruña, Madrid, Santander, Gijón, Valencia, Bilbao, San Sebastián, Logroño, Tarragona y Málaga. 


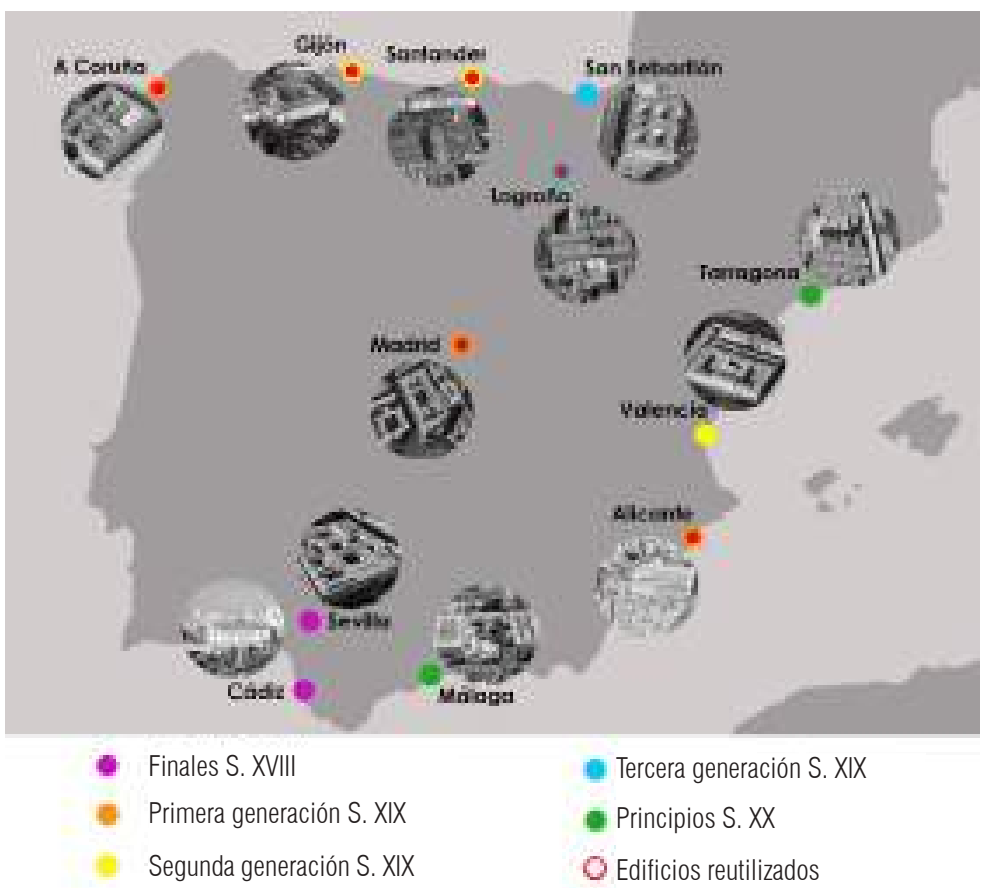

Figura 1.

Distribución geográfica de los casos de estudio abordados en la investigación general de la autora sobre las fábricas de tabacos en España como patrimonio industrial

Fuente: Elaboración propia

\section{EL PATIO EN LAS FÁBricas de tabacos EN ESPAÑA: RECURSO ESPACIAL DE ORGANIZACIÓN, CONTROL Y REPRESENTATIVIDAD}

En los primeros momentos de expansión del monopolio hacendístico tabacalero en España, y ante la necesidad de darle apoyo mediante la expansión territorial de los edificios productivos, se produjo una reflexión conceptual por parte de los proyectistas que acometerían esta tarea, abordando la cuestión de la concreción del espacio fabril tabacalero como tema arquitectónico del que no existían precedentes. Como fruto de estos planteamientos proyectuales de partida, surgiría una serie de invariantes arquitectónicos que perdurarían a lo 
largo del tiempo y se establecerían como una suerte de premisas proyectuales comunes en la definición espacial de las fábricas de tabacos en España.

La relevancia del patio como elemento espacial compositivo recurrente tiene su explicación en el papel que desempeñaría como sistema articulador del funcionamiento fabril y como uno de los elementos que sustentaría la significación de la propia arquitectura. De esta forma, la figura del patio en el seno de las tabacaleras españolas se puede interpretar como recurso compositivo de la organización espacial en la distribución de las dinámicas de producción, como medio para garantizar el control del producto y de la mano de obra y como elemento que denota la representatividad del conjunto fabril como fundación real respecto a las restantes arquitecturas industriales.

Los inmuebles que albergaron la actividad productiva del tabaco se materializaron según una configuración claustral en torno a patios que constituían el principio ordenador del conjunto, proporcionando luz y ventilación al interior de las estancias de laboreo. Además de organizar racionalmente el espacio interior, el patio se establecía como una pieza clave del proceso productivo tabacalero, puesto que la condición manufacturera de las fábricas tabacaleras requería espacios abiertos y provistos de instalaciones que surtiesen de agua a las labores desarrolladas en ellos².

Por otra parte, el empleo del patio como elemento de ordenación espacial garantizaba la clausura respecto al ámbito exterior, y el espacio interior se erigía como un instrumento de control del preciado producto y del personal empleado a través de la confluencia de recorridos hacia el interior y hacia un único acceso en el que se establecía un riguroso registro. De igual forma, a través de la ubicación de la vivienda del director y de las estancias de administración, en una posición que mediaba entre el acceso principal y el patio de ingreso, se garantizaba el control visual directo del espacio fabril por parte de la cúspide jerárquica de estos establecimientos industriales.

2 Tal es el caso de las operaciones de secado de la hoja, moja -humectación de la hoja seca para dotarla de trabajabilidad-y oreo del tabaco -secado posterior a la moja, que eliminaba el exceso de humedad-, o de la clasificación de las hojas de tabaco según su idoneidad para la labor requerida, así como la coordinación de operaciones de carga y descarga de materia prima y producto final antes de su entrada en los almacenes. 

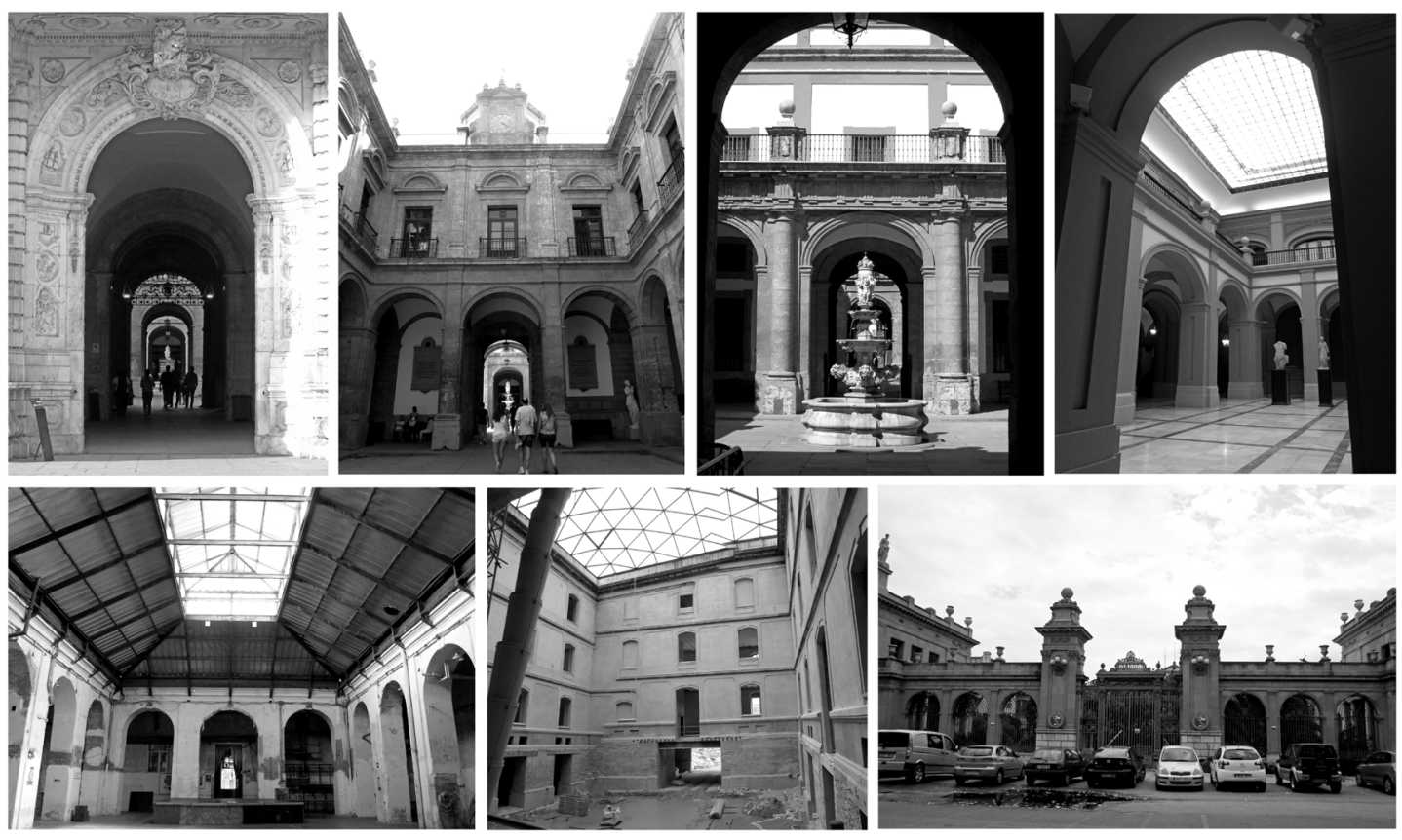

Figura 2.

El patio en las fábricas de tabacos en España. En la parte superior, la concatenación de patios en la Real Fábrica de Tabacos de Sevilla: vista desde la portada del acceso principal, patio del Reloj, patio de la Fuente y patio cubierto con montera acristalada. En la parte inferior, patio lateral sur de la Fábrica de Tabacos de Madrid, patio noroeste de la Fábrica de Tabacos de San Sebastián y puerta de acceso a la gran plaza de la Fábrica de Tabacos de Tarragona.

Fuente: Elaboración propia

Cabe destacar, asimismo, que el empleo del patio y su tratamiento compositivo a través de un lenguaje solemne y de cierta monumentalidad, garantizaba la significación del inmueble como industria auspiciada por la Corona. La jerarquización de los espacios que articulaban el interior de las fábricas tabacaleras permitía la creación de patios de honor en los accesos, que potenciaba una imagen de ecos palaciegos y que aunaba los significados de relevancia del conjunto industrial. 
A lo largo de la historia de las fundaciones fabriles tabacaleras en España, el patio como recurso compositivo dio lugar a configuraciones muy diversas en su relación con los requerimientos espaciales de la producción. Un notable ejemplo es el de la Real Fábrica de Tabacos de Sevilla, que inició su actividad en 1750 y en la cual la concatenación de patios que seguía un eje principal compositivo reforzaba un recorrido secuencial interior (Morales, 1991), trascendiendo la mera articulación del espacio fabril. De igual forma, la Fábrica de Tabacos de Madrid -que ocupó en 1809 el edificio proyectado por Manuel de la Ballina en 1780, como Real Fábrica de Aguardientes y Naipes- materializaría un sistema jerarquizado compuesto por un patio de honor central que marcaba el acceso principal, flanqueado por dos patios laterales de servicio, reiterando soluciones existentes como la del Cuartel del Conde Duque (Urrutia, 1982).

Por su parte, el proyecto de nueva planta de la Fábrica de Tabacos de San Sebastián, de 1886 (Gárate, 2006), emplearía una nueva variación de la configuración claustral a través de cuatro patios principales separados por un cuerpo cruciforme, que marcaría el inicio de un giro en el planteamiento proyectual de las tabacaleras hacia una menor compactación del inmueble. Esta mayor racionalización del espacio productivo a través de la desagregación del modelo compacto, culminaría en los proyectos de las fábricas de tabacos de Tarragona y Málaga de 1923 (Muiños, 2008), en las que el patio, como espacio central de distribución, expandía su escala y adoptaba la entidad de una gran plaza que articulaba los diversos pabellones en los que se materializaba, de forma separada, cada una de las funciones productivas.

A la luz de las consideraciones anteriores, cabe destacar que el empleo recurrente del patio como elemento ordenador de la arquitectura fabril tabacalera en España, remite a las circunstancias particulares históricas en las que se abordaron los primeros planteamientos proyectuales industriales. Ante la falta de referentes culturales en el siglo XVIII, de un modelo específico de arquitectura industrial, los proyectistas que asumían esta tarea -ingenieros militares en su mayor parte- buscaban referentes en la tradición arquitectónica, inspirándose en otros tipos de la arquitectura culta, que, de alguna forma, respondían a los requerimientos espaciales de la nueva temática industrial (Hernando, 1989). Las características de estos referentes tipológicos, 

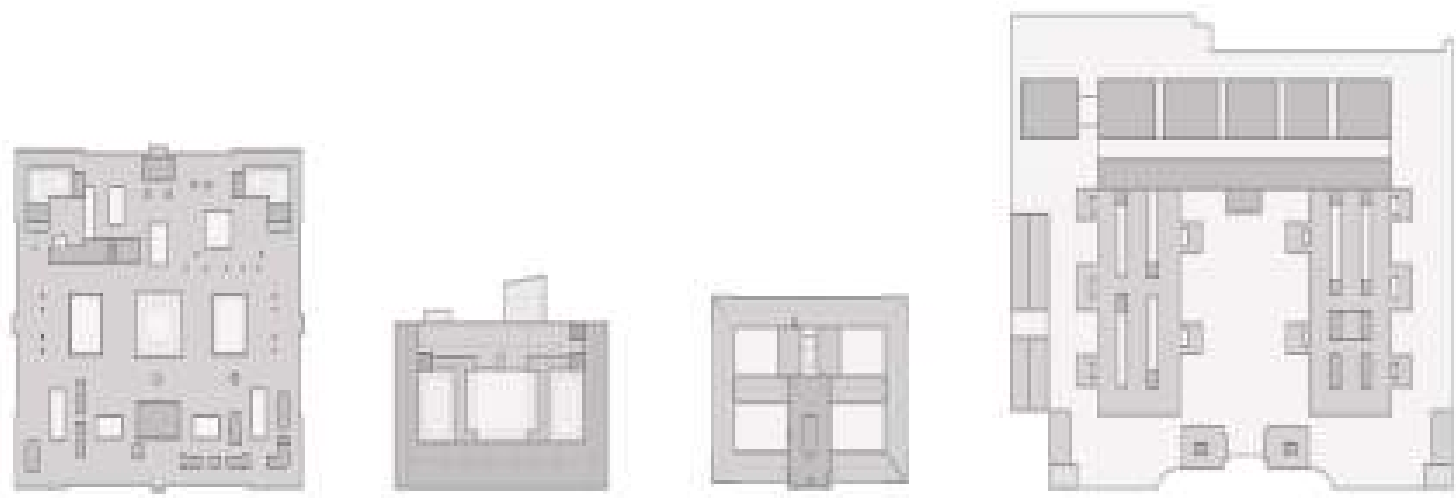

Figura 3.

El patio en los esquemas compositivos en planta de las fábricas de tabacos de Sevilla, Madrid,

San Sebastián y Tarragona

Fuente: Elaboración propia

combinadas con otros modelos ensayados en el extranjero -en el caso de las fábricas de tabacos, especialmente el ejemplo francés-, producirían una casuística particular de las arquitecturas fabriles tabacaleras en España.

De esta forma, la permanencia del patio remite a la toma de referentes tipológicos en modelos de espacios coercitivos -como conventos, cuarteles, cárceles, etc.-, como esquemas configuradores que responden al alojamiento de una ingente cantidad de personas en un espacio que debe garantizar el control y disponer de unos recursos espaciales de vigilancia tanto de sus ocupantes como del producto elaborado. Por ello, la lógica de la proyección espacial obedecía a la voluntad racionalizadora del proceso de producción y a una suerte de acción moralizante del espacio, de forma que tras la fachada de carácter palaciego se escondía un auténtico espacio de reclusión que garantizaba el orden y la disciplina (Selvafolta, 1985).

El patio es también elemento configurador de las tipologías palaciegas que, como modelos de inspiración, enfatizaban la representatividad que se quería otorgar a las fábricas de tabacos en España. Por tanto, el esquema claustral como principio ordenador no sólo remite a una tipología doméstica palaciega, sino que, a lo largo de la historia, también ha servido para estructurar con 
ligeras variantes muchos edificios con diversas funciones, tanto militares como civiles o religiosas, y en el caso de las fábricas de tabacos en España ha servido como esquema compositivo que se puede interpretar desde una triple óptica: funcional, coercitiva y representativa.

\section{APROXIMACIONES A LA ARQUITECTURA DE LAS FÁBRICAS DE TABACOS EN AMÉRICA: EL PATIO EN LA "CIUDADELA" MEXICANA Y EN LA REAL FÁBRICA DE TABACOS DE LIMA}

El continente americano contó con notables exponentes en materia de arquitectura fabril del tabaco, que surgirían en la segunda mitad del siglo XVIII con la política de fomento industrial de los Borbones, especialmente a través de las medidas modernizadoras de Carlos III, en términos de una incipiente industrialización. Si bien no fueron muy numerosos, su importancia radica en la apertura de nuevas temáticas arquitectónicas en América, que se verían muy influidas por los planteamientos proyectuales venidos de la península ibérica, y que en su conjunción con el lenguaje empleado en la producción arquitectónica colonial abrirían las puertas a un nuevo tipo arquitectónico industrial (Gutiérrez, 1983).

Nuevamente, el patio como principio configurado del espacio fabril establecería la articulación tanto de las circulaciones del producto como del personal empleado. De ello darían cuenta ejemplos destacables en el seno monopolístico, como la Dirección de Tabaco de Buenos Aires de 1781, y en el ámbito de la iniciativa privada, como las célebres fábricas de cigarros y habaneras de Calixto López de 1886 y la Fábrica de Tabacos "Partagás", fundada en la época de entre-siglos. Al objeto que ocupa el presente artículo, conviene señalar dos ejemplos de fundaciones reales que demuestran la relación entre los planteamientos proyectuales de las fábricas de tabacos en España y las primeras fundaciones fabriles tabacaleras en América: las reales fábricas de tabacos de México y Lima.

La tabacalera mexicana conocida como la "Ciudadela" fue proyectada en 1792 por el arquitecto Antonio González Velásquez, procedente de la Real Academia de San Carlos de México, concluyéndose los trabajos de construcción en 1807, con la colaboración del ingeniero Miguel Constanzó (Gutiérrez, 1983).Actualmente, y tras diversos cambios de uso como cuartel 
general y cárcel³ , el edificio se recuperó como biblioteca en el año 1946, por iniciativa de José Vasconcelos.

El inmueble se articuló mediante cuatro patios rodeados por corredores aporticados que definían un volumen cruciforme en cuya intersección se ubicaba el cernidor, empleando sus azoteas como secaderos. Completando los cuatro patios principales cuadrangulares, se situaban dos patios auxiliares en el eje compositivo desde el acceso principal oriental, que permitían el oreo del tabaco. Este eje reforzaba su importancia por el hecho de articular y concentrar en dicho acceso algunos de los espacios más significativos para el funcionamiento de la factoría: las oficinas de tesorería y contaduría, así como las estancias de control de acceso, disponiendo los almacenes y patios de labores en la parte trasera.

El cinturón perimetral se componía de diversos espacios diáfanos de traza rectangular, y establecía una clara separación por sexos de las estancias de labores de cigarros y puros, de tal manera que las de hombres se ubicaban en la mitad norte respecto al eje central, mientras que las de mujeres se disponían en la parte sur. Estos espacios productivos se completaban con estancias para el picado del tabaco, la creación de sellos o el encajonado de las labores.

El proyecto de la Real Fábrica de Tabacos de México presentaba algunas similitudes con la fábrica sevillana. Las diversas viviendas de las autoridades se ubicaban en las cuatro esquinas del inmueble, avanzando levemente su plano de fachada respecto al lienzo principal, produciéndose un leve retranqueo; de igual forma, todas ellas contaban con su propio patio interior. Por otra parte, la cimentación fue realizada a través de bóvedas, con el objeto de evitar la perjudicial humedad que alteraría las propiedades de la materia prima.

En cuanto al empleo del patio como elemento de ordenación de la composición, la distribución espacial de la tabacalera mexicana remite

3 Al igual que en las tabacaleras españolas, el origen manufacturero del edificio producía una suerte de indeterminación programática que permitía su reutilización para otros usos, principalmente coercitivos. En el caso de la fábrica mexicana, tras el cese de la actividad productiva tabacalera se reconvirtió en cuartel y cárcel, uso del que tomó el nombre de "Ciudadela", con el que se la conoce popularmente. 

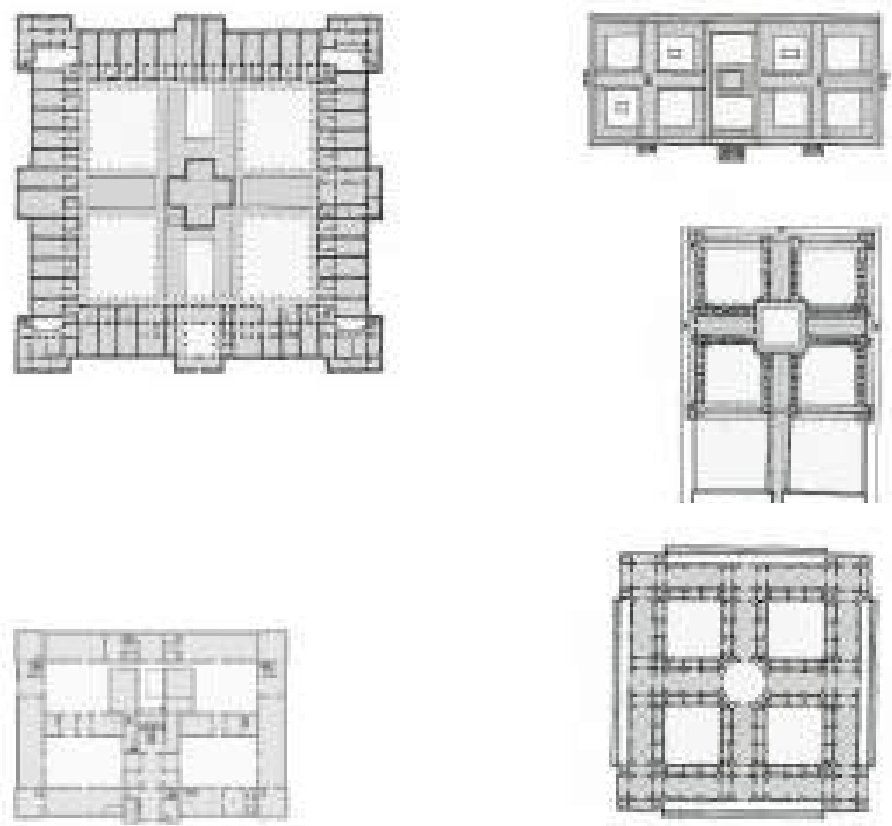

Figura 4.

Planta de la Real Fábrica de Tabacos de México a partir del proyecto de Antonio Velásquez, custodiado en el Archivo General de Indias. En la parte inferior, planta del proyecto de Mauro Serret para la Fábrica de Tabacos de San Sebastián. A la derecha y desde la parte superior, esquemas de la planta del proyecto de Filarete para el Ospedale Maggiore di Milano, la propuesta para un hospital de Philibert Delorme en su Ouvre entière de 1626 y la propuesta de Jean-Nicolas-Louis Durand para un museo en la obra Précis des leçons d'architecture donées a l'Ecole Polytechnique de 1819.

Fuente: Elaboración propia

a referentes arquitectónicos con esquemas similares, como ciertos tipos hospitalarios de los siglos XV y XVI ${ }^{4}$ (Pevsner, 1979) y algunas propuestas

4 El plan para el Ospedale Maggiore di Milano del Tratado de Filarete de mediados del siglo XV, o el diseño para un hospital de Philibert Delorme, de sus obras completas de principios del siglo XVII, emplean este esquema espacial de edificio compacto que se esponja con cuatro patios, definiendo un volumen cruciforme interior. 
tipológicas para museos del compendio de lecciones de J.-N.-L. Durand (Durand, 1819). Por otra parte, la configuración interior de la fábrica mexicana recuerda a la distribución empleada un siglo después en la Fábrica de Tabacos de San Sebastián ${ }^{5}$.

El caso de la Real Fábrica de Tabacos de Lima comporta otras particularidades. $\mathrm{Si}$ bien no se conservan vestigios materiales que permitan conocer su configuración espacial final, se sabe que el recinto fabril se encontraba frente a la actual Casona de San Marcos, en el área denominada como Chacarilla de San Bernardo, aproximadamente en el lugar que actualmente ocupa el edificio Alzamora Valdez (Burneo, 2002). El origen de la actividad productiva y la venta del tabaco en la ciudad de Lima data de mediados del siglo XVIII, y en su origen se repartía en diversos estanquillos ubicados en residencias particulares de la ciudad. Sin embargo, en 1780 se decide reagrupar la actividad tabacalera en un único edificio, ubicado en las antiguas huertas conventuales de los jesuitas, que habían sido expulsados en 1767 (Burneo, 2002).

Partiendo del análisis del proyecto de 1786 deVicente deVeza, cuya planimetría conservada documenta profusamente el funcionamiento espacial de la fábrica, se puede afirmar que la fábrica limeña presentaba una distribución completamente diversa a la de la tabacalera mexicana ${ }^{6}$. El complejo general se desdoblaba en dos sistemas espaciales conectados entre sí, y se accedía por la fachada principal a través de una portada barroca que, mediante una estancia intermedia, daba paso al primer sistema de espacios.

5 El hecho de que la fábrica mexicana date de mediados del siglo XVIII y que la fábrica donostiarra fuese concebida a finales del XIX, demuestra el empleo de recursos proyectuales anacrónicos en las tabacaleras de nueva planta españolas, como signo identificativo de la empresa en su materialización arquitectónica.

6 Si bien la falta de vestigios materiales impide constatar si la construcción siguió fielmente el proyecto de Vicente de Veza, se sabe que el complejo lindaba con fincas particulares al oeste y con el desaparecido convento de Santa Teresa al este -que se encontraba en la intersección de los actuales jirón Puno y avenida Abancay-. El único inmueble que ha llegado a nuestros días es el edificio del Estanco del Tabaco y la Sal, de la tercera década del siglo XX, que se construyó en el espacio anteriormente ocupado por la Alameda de Acho, junto al Rímac. 
Este sistema se estructuraba gracias a una sucesión de tres patios cuadrangulares aporticados de iguales dimensiones, que se destinaban a patio de honor, patio de almacenes y patio de administración, y que marcaban la dirección del eje principal desde el acceso. De esta forma, en torno al primer patio se aglutinaban la casa del administrador de almacenes y el denominado laboratorio de mujeres, así como las principales comunicaciones verticales a la primera planta. El segundo patio concentraba en su perímetro veinticinco almacenes, y el tercero, estancias destinadas al cuerpo de guardia y la administración de la fábrica. Como filtro de separación entre los tres patios se disponían dos volúmenes: el primero alojaba las dependencias de la casa del tesorero y el segundo estancias para la administración de almacenes. A través del tercer patio se podía acceder al jardín que lindaba con las huertas del convento de Santa Teresa, y al segundo sistema espacial.

La organización de este segundo conjunto espacial resulta menos clara. Desde el paso anteriormente mencionado se llegaba a un gran patio cuadrangular denominado "patio de la fábrica de cigarros", que contaba con mayores dimensiones que los tres anteriores. Este gran espacio determinaba la zonificación del segundo sistema, y disponía, en la parte trasera del conjunto, la fabricación de puros y picadura de tabaco, y en la parte cercana al acceso, la elaboración de cigarros de papel. Finalmente, las estancias cercanas a la fachada principal se destinaban a diversas necesidades para las mujeres empleadas en la fábrica.

En la crujía de la fachada principal, además de espacios de registro y control, administración y cuartos para el cuerpo de guardia, se disponía una serie de estancias que daban directamente a la vía pública, destinadas a puestos de venta. Los únicos accesos al complejo, desde el exterior, eran la entrada principal, a través de la portada barroca, y una entrada auxiliar situada a la derecha de la fachada principal, que comunicaba directamente con los espacios de elaboración.

Cabe destacar el interés de la sucesión jerarquizada de patios aporticados en el primer sistema de espacios de la fábrica limeña, en su relación con el esquema organizador de la tabacalera madrileña. Ciertamente, su distribución es semejante, con la excepción de que en el caso español el acceso se realizaba a través del patio de honor central, relegando los dos espacios laterales a 

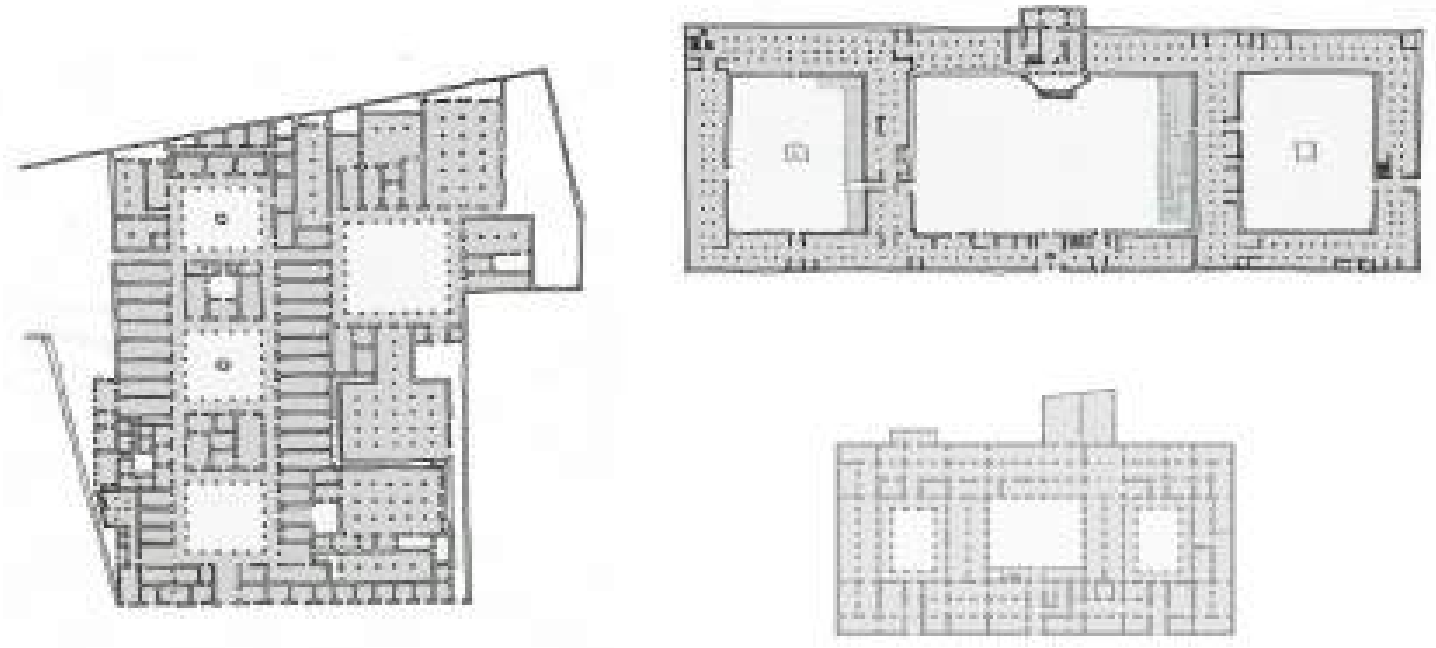

Figura 5.

Planta de la Real Fábrica de Tabacos de Lima a partir del proyecto de Vicente de Veza, custodiado en el Archivo General de Indias. A la derecha, planta del Cuartel del Conde Duque proyectado por Pedro de Ribera en 1717, y en la parte inferior, planta de la Fábrica de Tabacos de Madrid.

Fuente: Elaboración propia

su función auxiliar al servicio de las labores productivas. De esta forma se observa cómo esta configuración tripartita de patios era un planteamiento recurrente, tanto de espacios fabriles como de inmuebles cuartelarios, tal y como se apuntaba en el epígrafe anterior sobre la relación de este esquema entre la Fábrica de Tabacos de Madrid y el Cuartel del Conde Duque.

Esto viene a confirmar que las similitudes de los planteamientos proyectuales de los primeros momentos de la industria, con esquemas procedentes de otros tipos arquitectónicos, son síntoma de la búsqueda de referentes culturales por parte de los proyectistas que acometían la tarea de materializar constructivamente y dar respuesta a la nueva función arquitectónica. A ello coadyuvaba el hecho de que el carácter manufacturero de la producción tabacalera en sus inicios facilitaba 
la concepción espacial y la inserción del proceso de elaboración en tipos edilicios compactos, organizados mediante patios interiores que articulaban estancias diáfanas para el alojo de una ingente mano de obra que operaba sobre la materia prima de forma manual.

\section{CONCLUSIONES}

A lo largo del presente artículo se ha analizado el papel del patio como recurso espacial configurador de las fábricas de tabacos en España y el empleo de este esquema en los casos americanos. Se trata de una arquitectura industrial que bebe de sus orígenes manufactureros, de la tradición histórica arquitectónica y de la herencia de una serie de consideraciones proyectuales que entroncan directamente con los primeros planteamientos de la arquitectura industrial, en una época en la que esta nueva función planteaba la búsqueda de referentes en otros tipos de arquitectura culta, ante la falta de precedentes sobre una tipología fabril.

En su traslado a la producción tabacalera americana durante el siglo XVIII, se observa cómo el empleo de esquemas claustrales apoyados en la simetría y racionalidad de la distribución espacial, permite adoptar una configuración que conceptualmente se consideraba como la más idónea para albergar la nueva función industrial. Sin embargo, mientras que en España se emplearon como recurso proyectual hasta mediados del siglo XX los invariantes arquitectónicos emanados de los primeros planteamientos fabriles tabacaleros, la independencia de las colonias americanas permitió, a lo largo del XIX, una formalización arquitectónica en términos más libres en las fundaciones fabriles tabacaleras.

\section{REFERENCIAS}

Burneo, R.A. (2002). Orígenes y evolución del conjunto arquitectónico de la Casona de San Marcos (Programa para la Conservación del Patrimonio Cultural, Universidad Nacional Mayor de San Marcos, Agencia Española de Cooperación Internacional, Instituto Nacional de Cultura). Lima: Fondo Editorial de la UNMSM. 
Durand, J-N-L. (1981 [1819]). Compendio de lecciones de arquitectura. Parte gráfica de los cursos de arquitectura. Madrid: Pronaos.

Gárate Ojanguren, M. (2006). La fábrica de tabacos de San Sebastián. Historia y estrategia empresarial: 1878-2003. España: Fundación Altadis.

Gutiérrez,R.(1983).La arquitectura de gobierno.En R. Gutiérrez, Arquitectura y urbanismo en Iberoamérica (pp. 275-298). Madrid: Cátedra.

Hernando, J. (1989). La arquitectura industrial. En J. Hernando, Arquitectura en España 1770-1900 (pp. 353-371). Madrid: Cátedra.

Morales Sánchez, J. (1991). La Real Fábrica de Tabacos: arquitectura, territorio y ciudad en la Sevilla del siglo XVIII. Sevilla: Fundación Fondo de Cultura de Sevilla.

MuiñosVillaverde, M.J. (2008). La realidad de un mito:la Fábrica de Tabacos de Tarragona (1932-2007). Madrid: Dirección de Comunicación de Altadis.

Pevsner, N. (1979). Historia de las tipologías arquitectónicas. Barcelona: Gustavo Gili.

Selvafolta, O. (septiembre 13, 1985). El espacio del trabajo (1750-1910). Debats. Institució Alfons El Magnánim. Institució Valenciana d’Estudis i Investigació (pp. 52-69). España.

Urrutia, A. (1982). La Real Fábrica de Aguardientes y Naipes. En Establecimientos tradicionales madrileños. Del Centro a las Rondas (tomo III, pp. 119-132). Madrid: Cámara de Comercio e Industria. 